\title{
Biosorption of Copper (II) from Simulated Wastewater Using Spent Coffee Grounds: A Column Study
}

\author{
Aileen D. Nieva, Reuben James Q. Buenafe, Drex R. Guinto, and Jean Claudine F. Leaño
}

\begin{abstract}
Biosorption of contaminant like copper using agricultural wastes like spent coffee grounds requires testing the compatibility of the sorbents with the sorbates and finding the optimum conditions for the process. This study is needed to avoid the disruptive effects of biosorption such as the generation of more wastes that eventually disrupts the balance in the environment. This paper is a baseline study to optimize the performance of adsorption of copper in wastewater using two species of spent coffee grounds i.e., Arabica and Robusta. The adsorptive capacities of pure blends of both species were compared to the 50:50 blend in a fixed-bed column. It is aimed to determine the optimum bed height, coffee variety and flow rate inside the column to reduce waste generated through experiments. It was found out that the optimum conditions were $7 \mathrm{~cm}$ bed height and $20 \mathrm{~mL} / \mathrm{min}$ flow rate. The adsorptive capacities of the three varieties were $10.47,13$, and $15.41 \mathrm{mg} / \mathrm{g}$ for pure Arabica, 50:50 blend and pure Robusta, respectively.
\end{abstract}

Index Terms-Adsorptive capacities, agricultural wastes, biosorption, wastewater.

\section{INTRODUCTION}

Copper is found in various materials like coins, insecticides, fungicides, and on some aquarium products. Accidental intake of copper causes abdominal pain, diarrhea, vomiting, and jaundice. Long- term exposure to copper leads to lung inflammation, anemia, nausea, and pain [1]. Because of the continuous use of copper-containing products, toxicological problems caused by the copper to the environment and human health have become a challenge in research in recent years.

Adsorption is quite a sustainable alternative treatment in terms of its efficiency in the removal of heavy metals. The use of common adsorbents like activated carbon, zeolite, and clay is very popular due to their high adsorption capacity. However, because of their costs, biosorbents become better alternatives due to their high metal binding capacity, low operational cost, high efficiency in dilute effluents and eco-friendliness [2]. Studies show that agricultural wastes, which are supposed to be environmental problems can now be used in removing heavy metals and in detoxifying industrialmetal bearing effluents [3]. Agricultural wastes, such as bean husk [4], raw pine cone [5], durian tree sawdust, coconut coir, empty fruit bunch of oil palm [6], rice straw, pomelo peel [7], and agricultural solid waste-mentha [8] have already been used in adsorbing $\mathrm{Cu}^{2+}$ in water and the use of spent coffee is gaining much attention. Commercial coffee residues have been widely used in previous batch experiments as an

Manuscript received January 13, 2019; revised June 17, 2019.

The authors are with the School of Chemical, Biological, and Materials Engineering and Sciences, Mapua University, Muralla St., Intramuros, Manila, 1002, Philippines (e-mail: adnieva@mapua.edu.ph). effective biosorbent. Existing batch biosorption experiments evaluated the optimum parameters that affect the adsorbing capacity of coffee [9]-[13], which justified the effectivity and potential of the biosorbent while varying important adsorption parameters such as initial concentration and $\mathrm{pH}$ of the adsorbate [14]. Due to the potential of spent ground coffee as biosorbent to $\mathrm{Cu}^{2+}$ - laden effluents with batch adsorption process, this study aimed to determine the performance of a continuous fixed bed column and identified the column optimum parameters i.e. bed height and flow rate in adsorbing $\mathrm{Cu}^{2+}$ in simulated wastewater using spent Coffea canephora (Robusta coffee), spent Coffea arabica (Arabica coffee), and a 50:50 blend of these coffee residues. This study can be used as baseline studies for the adsorption of $\mathrm{Cu}^{2+}$ using spent coffee in a fixed bed column. Utilization of these optimum parameters would increase the efficiency of the column and thus would lessen generation of contaminated biosorbent while treating the wastewater efficiently.

\section{MATERIALS AND METHODS}

\section{A. Preparation of Adsorbate}

The adsorbate was prepared using stock $\mathrm{Cu}\left(\mathrm{NO}_{3}\right)_{2}$ crystals (98\% purity, Sigma-Aldrich) diluted with purified water to produce a solution with $18 \mathrm{mg} / \mathrm{mL} \mathrm{Cu}^{2+}$ metal concentration. The $\mathrm{pH}$ of the solution was adjusted to 5.0 using $0.1 \mathrm{M} \mathrm{NaOH}$ or $0.1 \mathrm{M} \mathrm{HCl}$ solution, whenever necessary.

\section{B. Preparation of Adsorbent}

Unspent coffee beans of medium roast Coffea arabica and Coffea canephora were bought from Garcia's Coffee located at Baguio City Public Market. The coffee beans were brewed using Hanabishi HCM 10B Coffee Maker. Spent coffee grounds were washed repeatedly with water until it became clear to remove unwanted matter and were oven-dried at $70{ }^{\circ} \mathrm{C}$ for five hours. Dried coffee samples were further milled using Thomas Scientific Wiley Mill and then sieved using a sieve shaker with a 35-mesh screen.

\section{Adsorbent Characterization}

Dried spent coffee grounds were characterized before adsorption by Fourier Transform Infrared Spectroscopy (FTIR, Perkin Elmer Spectrum 100) to identify the existing functional groups in the coffee samples. Also, the biosorbents were run through a Scanning Electron Microscope (SEM, Jeol JSM-5310) with a magnification of 2,000 to study the surface topography of the coffee samples.

\section{Continuous System Studies}

Spent coffee grounds were packed up to bed heights of 2.5 
$\mathrm{cm}, 5 \mathrm{~cm}$ and $7 \mathrm{~cm}$ situated in a chromatography column. The simulated wastewater was supplied to the column by using a peristaltic pump with a maximum capacity of $100 \mathrm{~mL} / \mathrm{min}$ and it was assumed that room temperature was at ambient temperature. The experiments were done at flow rates of 20 , 30 and $40 \mathrm{~mL} / \mathrm{min}$. A blank run using purified water was carried out for the calibration of the pump. The samples are collected within a 30-minute interval until the concentration achieves $90 \%$ of the initial concentration. The final metal ion concentrations were acquired by atomic absorption spectroscopy using Perkin Elmer AAnalyst100. A total of 27 trials were done with varying flow rates and bed heights.

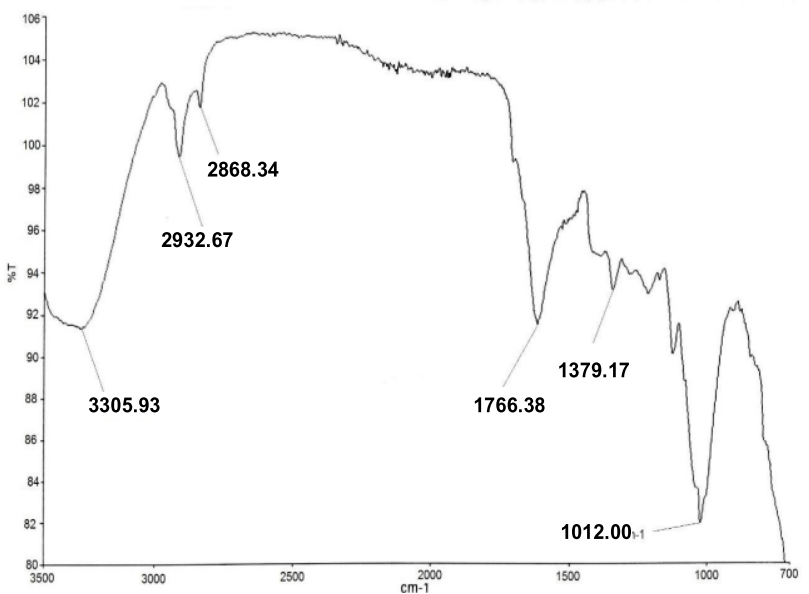

Fig. 1. FTIR spectrum of spent Arabica coffee grounds.

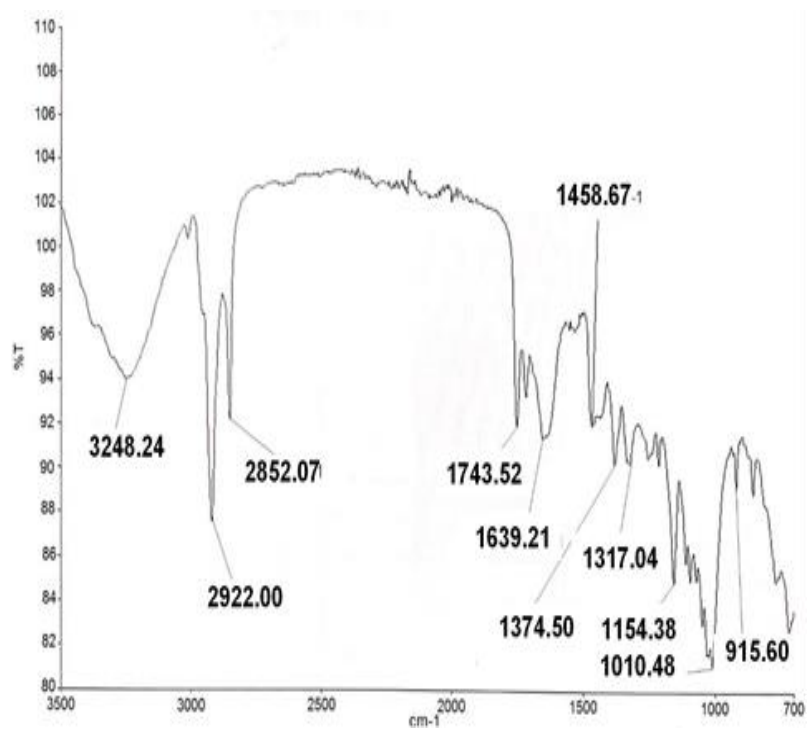

Fig. 2. FTIR spectrum of spent Robusta coffee grounds

\section{RESULTS AND DISCUSSIONS}

\section{A. Adsorbent Characterization}

Fig. 1 and Fig. 2 show the spectrum of the spent Arabica and Robusta coffee grounds sample. The presence of lignin was confirmed in the broad band at 3305.93 (Arabica) and 3248.24 (Robusta) $\mathrm{cm}^{-1}$, which is mainly attributed to O-H and N-H stretching [15]. The peak present in 1012 (Arabica) and 1030.89 (Robusta) $\mathrm{cm}^{-1}$ is attributed to the presence of lignin and cellulose due to C-O deformation [16]. Lignocellulosic materials are used in removing contaminants in water [17]. The cellulose and lignin contents of both the spent coffee varieties can further explain the adsorption process in the system and can prove that indeed these coffee varieties are feasible in adsorbing $\mathrm{Cu}^{2+}$ in wastewater.

The SEM micrographs before and after adsorption process in Fig. 3, 4, and 5 for Arabica, Robusta, and 50:50 blend revealed that adsorption of $\mathrm{Cu}^{2+}$ indeed happened due to the transition of rough surfaces of each of the adsorbent before adsorption to smooth surfaces after adsorption.

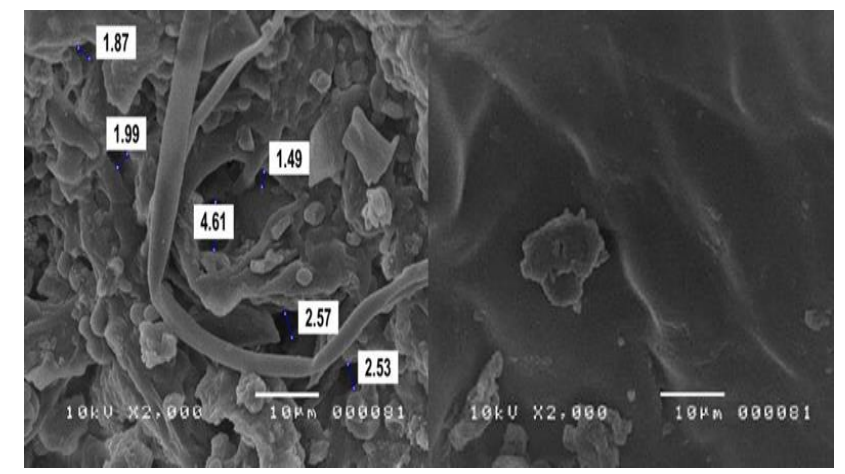

Fig. 3. SEM micrograph before and after adsorption of spent Arabica coffee grounds (left-before, right-after).

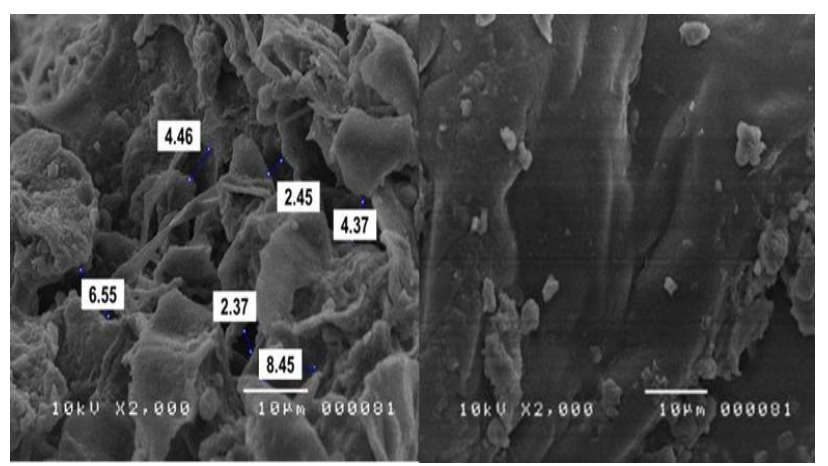

Fig. 4. SEM micrograph before and after adsorption of spent Robusta coffee grounds (left-before, right-after).

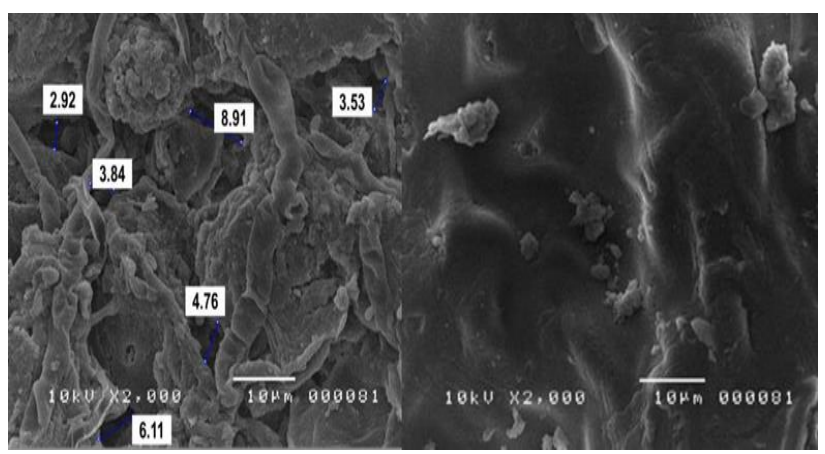

Fig. 5. SEM micrograph before and after adsorption of 50:50 blend spent coffee grounds (left-before, right-after).

\section{B. Adsorbent Characterization}

The biosorption of $\mathrm{Cu}^{2+}$ onto spent coffee grounds was studied by changing the heights of bed at $2.5 \mathrm{~cm}, 5 \mathrm{~cm}$, and 7 $\mathrm{cm}$ at $20 \mathrm{~mL} / \mathrm{min}$ flow rate and $18 \mathrm{mg} / \mathrm{L}$ initial metal concentration to identify the optimal bed height for each coffee variety. The column performance of the study is summarized in Table I Results showed that as the bed height increases, the value of the breakthrough time and the exhaustion time also increases.

The increase in the value of the breakthrough time is caused by the high dose of adsorbent in the column which resulted to the increase of possible active sites for copper adsorption [16]. 
This principle can be related to the breakthrough capacity of the adsorbent as shown in (1). The equation shows that the breakthrough time and the amount of sorbent are directly proportional to each other at a constant flow rate and feed concentration.

$$
\text { Capacity breakthrough }=\left(t_{b}\right)(v)\left(C_{0}\right) / m_{\text {adsorbent }}
$$

where $t_{b}$ is the breakthrough time, $v$ is the flow rate, $C_{0}$ is the concentration of the feed and $m_{\text {adsorbent }}$ is the amount of adsorbent.

TABLE I: COLUMN PERFORMANCE DATA AT A CONSTANT INLET CONCENTRATION $\left(\mathrm{C}_{0}\right)$ OF $18 \mathrm{Mg} / \mathrm{L}$ AND FLOW RATE OF $20 \mathrm{ML} / \mathrm{MIN}$

\begin{tabular}{llll}
\hline \hline Sample & Bed height $(\mathrm{cm})$ & $\begin{array}{l}\text { Breakthrough time } \\
(\mathrm{min})\end{array}$ & $\begin{array}{l}\text { Exhaustion time } \\
(\mathrm{min})\end{array}$ \\
\hline \multirow{3}{*}{ Arabica } & 2.5 & 51.97 & 362.4 \\
& 5 & 110.78 & 427.52 \\
& 2.5 & 177.74 & 528.56 \\
Robusta & 5 & 109.18 & 432.91 \\
& 7 & 188.15 & 509.94 \\
\multirow{4}{*}{ Mix } & 2.5 & 231.15 & 540.18 \\
& 5 & 80.53 & 406.77 \\
\hline \hline
\end{tabular}

Results showed that when the height of the bed is lowered the breakthrough and exhaustion point is reached earlier for the three samples. It showed that the optimal bed height for all the three samples is $7 \mathrm{~cm}$ wherein the Robusta coffee had the highest breakthrough time of 231.15 min. Based on the SEM micrographs, the pores present in each of the samples acts as the active site for the adsorption process. The ionic radius of copper is $7.3 \times 10^{-5} \mu \mathrm{m}$ which fits effectively to the pore size of Robusta coffee $(2.37-8.45 \mu \mathrm{m})$ which has a larger pore size than Arabica $(1.49-4.61 \mu \mathrm{m})$ and 50:50 blend $(2.92-6.11 \mu \mathrm{m})$. The high value of the breakthrough time indicates that more copper ions adhered to the pores of the biosorbent due to the large area of binding sites. Additionally, the FTIR spectra revealed that lignin is present in the biosorbent Lignin has a variety of functional groups that can perform as active sites for the surface of the biosorbent [18]. This confirms the increase in the value of the breakthrough time and validates the effectiveness of the spent coffee grounds.

\section{Optimization of Flow Rate}

The effect of varying volumetric flow rate was studied at 7 $\mathrm{cm}$ bed height and $18 \mathrm{mg} / \mathrm{L}$ initial metal concentration. The results are summarized in Table II. Results showed that lowering the flow rate increases the value of the breakthrough time and the exhaustion time, because the decrease in mobility of the fluid allows more time for the adsorbent and sorbate interaction and thus, decreasing the mass transfer of ions into the pores of the adsorbent. This minimizes the possibility of obstruction in the adsorbent's opening. On the other hand, higher flow rates denote lower sorption capacity because copper ions do not have enough contact time to bind with the biosorbent leaving the bed saturated before equilibrium [16].

Results show that higher flow rates reach the breakthrough and exhaustion points earlier as compared to lower flow rates for all the samples. Since the ionic radius of the copper is smaller than the pore sizes of the biosorbents. It is probable that a large number of copper ions would adhere to the coffee due to the increased flow of solution to the system. On the other hand, lower flow rates delayed the exhaustion time and the breakthrough time because the amount of sorbate entering the system is too low. Since the area of the active site is too large, a minimal flow would take time for copper ions to occupy the pores of the coffee. This causes the spent coffee grounds to be saturated with the copper ions at a longer time. Based on the results the Robusta coffee showed the best breakthrough time $(231.15 \mathrm{~min})$ at $20 \mathrm{~mL} / \mathrm{min}$ flow rate.

TABLE II: COLUMN PERFORMANCE DATA AT A CONSTANT INLET CONCENTRATION $\left(\mathrm{C}_{0}\right)$ OF $18 \mathrm{MG} / \mathrm{L}$ AND FlOW RATE OF $20 \mathrm{ML} / \mathrm{MIN}$

\begin{tabular}{llll}
\hline \hline Sample & $\begin{array}{l}\text { Flow rate } \\
\left(\mathrm{mL} \cdot \mathrm{min}^{-1}\right)\end{array}$ & $\begin{array}{l}\text { Breakthrough time } \\
(\mathrm{min})\end{array}$ & $\begin{array}{l}\text { Exhaustion time } \\
(\mathrm{min})\end{array}$ \\
\hline \multirow{3}{*}{ Arabica } & 20 & 177.74 & 528.56 \\
& 30 & 139.89 & 464.24 \\
& 40 & 113.56 & 417.43 \\
Robusta & 30 & 231.15 & 540.18 \\
& 40 & 196.69 & 518.65 \\
\multirow{4}{*}{ Mix } & 20 & 170.77 & 447.66 \\
& 30 & 202.61 & 538.43 \\
& 40 & 167.43 & 485.77 \\
\hline \hline
\end{tabular}

\section{Optimization of Coffee Variety}

Based on the results of the two optimization processes (flow rate and bed height), the Robusta coffee shows the best breakthrough and exhaustion time. The amount of adsorbent is proportional to the bed height and the high value of the breakthrough time which was obtained as 231.15 minutes is due to the optimization of the bed height itself which is $7 \mathrm{~cm}$ and the flow rate of $20 \mathrm{~mL} / \mathrm{min}$. On the other hand, the exhaustion time of 540.18 minutes only denotes that the Robusta sample has the highest adsorption capacity because it would take that much time before it wears out. Since the Robusta coffee has the highest capacity among the three coffee samples, it can be inferred that it possesses a vast number of binding sites available as shown in its SEM micrograph. Moreover, the presence of lignin from the FTIR spectra of the Robusta coffee also verifies its adsorption capacity.

\section{E. Dynamic Adsorption Model for the Determination of Adsorption Capacity}

The Thomas model, shown in (2), is used in describing the behavior of a fixed-bed column biosorption process. It indicates that the limiting step is not internal and external diffusion [19].

$$
\ln \left[\left(C_{0} / C_{t}\right)-1\right]=\left(k_{T H} \times q_{0} \times m / Q\right)-\left(k_{T H} \times C_{0} \times t\right)
$$

where $t$ stands for total flow time ( $\mathrm{min}$ ), $m$ was the dry weight of sorbent $(\mathrm{g}), C_{0}$ is the influent concentration $(\mathrm{mg} / \mathrm{L}), k_{T H}$ is the rate constant $(\mathrm{mL} / \mathrm{min} / \mathrm{mg}), C_{t}$ is the concentration of effluent $(\mathrm{mg} / \mathrm{L}), Q$ is the volumetric flow rate $(\mathrm{mL} / \mathrm{min})$, and $q_{0}$ is the adsorption capacity $(\mathrm{mg} / \mathrm{g})$.

The Yoon-Nelson model is given by the following equation: 


$$
\ln \left[C_{t} /\left(C_{0^{-}} C_{t}\right)\right]=\left(k_{Y N} \times t\right)-\left(k_{Y N} \times \tau\right)
$$

where kYN $_{Y N}$ is the rate constant $\left(\mathrm{min}^{-1}\right), \tau$ is the $50 \%$ adsorbate breakthrough time $(\mathrm{min})$ and $\mathrm{t}$ is the time of breakthrough (min).

The Bohart-Adams model assumes that equilibrium is not occurring at an instant. Thus, when the adsorption rate increases, the adsorption capacity also increases. This model was used for the description of the initial part of the breakthrough curve by estimation of characteristic parameters by using the following equation:

$$
\ln \left[C_{t} / C_{0}\right]=\left(k_{B A} \times C_{0} \times t\right)-\left(k_{B A} \times N_{0}\left(z / u_{0}\right)\right)
$$

where $u_{0}$ is the linear velocity $(\mathrm{cm} / \mathrm{min}), z$ is the bed depth (cm), $N_{0}$ is the maximum bed volumetric sorption capacity $(\mathrm{mg} / \mathrm{L})$, and $k_{B A}$ is the rate constant $(\mathrm{L} / \mathrm{mg}-\mathrm{min})$.

To identify the best fit model, the breakthrough curve is plotted against the non-linear models. Fig. 6 shows the comparison of the breakthrough curve to the dynamic models used. The curve of the Bohart-Adams dynamic model follows the same points as the breakthrough curve in the first half of the curve. This validates that the Bohart-Adams dynamic model only describes the initial part of the breakthrough curve. The opposite trend was observed in the Thomas dynamic model wherein the curve only described the latter part of the breakthrough curve. The curve of the Yoon-Nelson dynamic model best describes the breakthrough data because it follows the same points as the breakthrough curve in both the initial and the latter part of the curve. It means that the breakthrough of the sorbate on the sorbent is directly proportional to the rate of decrease in the probability of adsorption [19].

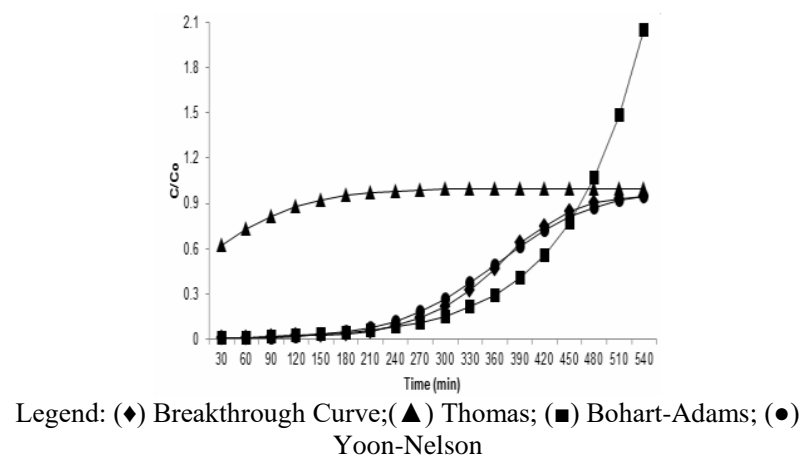

Fig. 6. Comparison of the breakthrough curve to the three dynamic models.

TABLE III: DyNAMIC ADSORPTION MODEL PARAMETERS AT A CONSTANT INLET CONCENTRATION $\left(\mathrm{C}_{0}\right)$ OF $18 \mathrm{MG} / \mathrm{L}$, BED HEIGHT OF $7 \mathrm{CM}$, AND FLOW RATE OF 20 ML/MIN

\begin{tabular}{llll}
\hline \hline \multirow{2}{*}{ Model } & Sample & $\begin{array}{l}\mathrm{K}_{\mathrm{TH}} \\
\left(\mathrm{mL} \cdot \mathrm{min}^{-1} \cdot \mathrm{mg}^{-1}\right)\end{array}$ & $\begin{array}{l}\mathrm{q}_{0} \\
\left(\mathrm{mg} \cdot \mathrm{g}^{-1}\right)\end{array}$ \\
\hline \multirow{3}{*}{ Thomas } & Arabica & $9.02 \times 10^{-4}$ & 10.47 \\
& Robusta & $9.32 \times 10^{-4}$ & 15.41 \\
& Mix & $9.23 \times 10^{-4}$ & 13.00 \\
& & $\mathrm{~K}_{\mathrm{YN}}$ & $\tau$ \\
& & $\left(\mathrm{min}^{-1}\right)$ & $(\mathrm{min})$ \\
\hline \multirow{3}{*}{ Yoon-Nelson } & Arabica & $4.65 \times 10^{-3}$ & 394.93 \\
& Robusta & $7.37 \times 10^{-3}$ & 444.40 \\
& Mix & $5.89 \times 10^{-3}$ & 462.22 \\
& & $\mathrm{~K}_{\mathrm{BA}}$ & $\mathrm{N}_{0}$ \\
& & $\left(\mathrm{~L} \cdot \mathrm{mg}^{-1} \cdot \mathrm{min}^{-1}\right)$ & $(\mathrm{mg} \cdot \mathrm{L})$ \\
\hline \multirow{3}{*}{ Bohart-Adams } & Arabica & $2.64 \times 10^{-4}$ & 174.18 \\
& Robusta & $4.18 \times 10^{-4}$ & 180.32 \\
& Mix & $3.34 \times 10^{-4}$ & 177.16 \\
\hline \hline
\end{tabular}

The parameters resulted using the three models at the optimal bed $(7 \mathrm{~cm})$ height and flow rate $(20 \mathrm{~mL} / \mathrm{min})$ is summarized in Table III The results showed that the adsorptive capacities of the three samples based on Thomas Model can be arranged in the following increasing order: $10.47 \mathrm{mg} / \mathrm{g}$ for the Arabica coffee, $13 \mathrm{mg} / \mathrm{g}$ for the $50-50$ blend and $15.41 \mathrm{mg} / \mathrm{g}$ for the Robusta coffee.

\section{CONCLUSIONS}

The biosorption of copper ions from simulated wastewater solution on different varieties of spent coffee grounds namely, Arabica (Coffea arabica), Robusta (Coffea canephora) and the 50-50 blend of the two samples has been studied. The present study determined that Robusta coffee is the best biosorbent among the three samples because of its high breakthrough time that is shown in the dynamic models. Optimization, which was the main objective of the study, was achieved as copper ions were adsorbed effectively at the most feasible parameters $(20 \mathrm{~mL} / \mathrm{min}$ influent flow rate, $7 \mathrm{~cm}$ bed height). Among the four dynamic models used, the Yoon-Nelson model had the best fit for the optimized parameter. Breakthrough time increased as the height of bed increased and adsorption capacity, $\mathrm{q}_{0}$ increased as the flow rate increased, since contact time between the fluid and adsorbent decreased. Also, the time required for $50 \%$ adsorbate breakthrough, $\tau$, increased as the bed height increased.

The FTIR results revealed that if more functional groups are present in a sample like in Robusta coffee, it translates to an effective biosorption. On the other hand, the SEM micrographs showed the presence of small and large particle sizes in the spent coffee grounds along with its porous surfaces which act as the active sites for the biosorption. It was discovered that the factors influencing the biosorption were statistically significant. It can be concluded that spent coffee grounds can be an efficient biosorbent for removing copper ions in wastewater and its baseline parameters when it will be used in adsorption column was already established based on the results of this study.

\section{CONFLICT OF INTEREST}

The authors declare no conflict of interest.

\section{AUTHOR CONTRIBUTIONS}

Aileen D. Nieva facilitated and conceptualized the whole research process and write-ups construction; Reuben James Q. Buenafe edited and proofread the final paper; Drex R. Guinto and Jean Claudine F. Leaño conducted the research, analyzed the data, and wrote the paper; all authors approved the final revision of the paper.

\section{REFERENCES}

[1] P.D. Constable, K. W. Hinchcliff, S. H. Done, and W. Grünberg, Veterinary Medicine, 1993, ch. 11, pp. 716-844.

[2] D. Sud, G. Mahajan, and M. P. Kaur, "Agricultural waste material as potential adsorbent for sequestering heavy metal ions from aqueous solution - A review," Bioresource Technology, 2008.

[3] G. O. Adediran, A. Tella, and H. A. Mohammed, "Adsorption of Pb, Cd, $\mathrm{Zn}, \mathrm{Cu}$ and $\mathrm{Hg}$ ions on formaldehyde and pyridine modified bean husks," J. Appl. Sci. Environ. Manag, vol. 11, 2007. 
[4] A. Adeyanmo, K. Adebowale, and B. Olu-Owalabi, Am. Chem. Sci. J., vol. 4, pp. 992-1000, 2014.

[5] S. Najiah et al., "Removal of $\mathrm{Cu}(\mathrm{II}), \mathrm{Pb}(\mathrm{II})$ and $\mathrm{Zn}$ (II) ions from aqueous solutions using selected agricultural wastes: adsorption and characterization studies," J. Environ, Prot., vol. 5, pp. 289-300, 2014.

[6] P. Tasaso, "Adsorption of copper using pomelo peel and depectinated pomelo peel, “ J. Clean Energy Technol., vol. 2, pp. 154-157, 2014.

[7] R. Ahmad and S. Hasseb, "Adsorption of $\mathrm{Cu} 2+$ from aqueous solution onto agricultural solid waste-mentha: Characterization, isotherms, and kinetic studies," J. Dispers. Sci. Technol., vol. 33, pp. 1188-1196, 2012.

[8] S. Kyzas, "Commercial coffee wastes as materials for adsorption of heavy metals from aqueous solutions," Materials, vol. 5, pp. 1826-1840, 2012.

[9] C. H. Wu, C. Y. Kuo, and S. S. Guan, "Adsorption of heavy metals from aqueous solutions by waste coffee residues: Kinetics, equilibrium, and thermodynamics," Desalin. Water Treat., vol. 57, pp. 5056-5064, 2016.

[10] C. H. Wu, C. Y. Kuo, and S. S. Guan, "Adsorption kinetics of lead and zinc ions by coffee residues," Polish J. Environ. Stud., vol. 24, pp. 761-767, 2015.

[11] W. L. Chou, C. T. Wang, K. Y. Huang, Y. C. Chang, and C. M. Shu, "Investigation of indium ions removal from aqueous solutions using spent coffee grounds," Int. J. Phys. Sci., vol. 7, pp. 2445-2454, 2012.

[12] T. Thuy, L. Thi, and K. Le Van, "Adsorption behavior of Pb(II) in aqueous solution using coffee husk-based activated carbon modified by nitric acid," Am. J. Eng. Res., pp. 120-129, 2016.

[13] J. Seniūnaitè, R. Vaiškūnaitè, and V. Bolutienè, "Coffee grounds as an adsorbent for copper and lead removal from aqueous solutions," in Proc. $9^{\text {th }}$ Conf. Environ. Eng., 2014.

[14] J. M. Barcelo et al., "FTIR spectrum and antimutagenicity of coffea arabica pulp and arachis hypogaea testa in relation to their in vitro antioxidant properties," Asia Pacific J. Multidisc. Res., vol. 4, pp. 99-108, 2015.

[15] R. M. Correia et al., "Chemical profiles of robusta and arabica coffee by ESI(-)FT-ICR MS and ATR-FTIR: A quantitative approach,” Anal. Methods, vol. 8, pp. 7678-7688, 2016.

[16] N. E. Dabila-Guzman, F. Cerino-Cordova, M. Loredo-Cancino, J. Rangel-Mendez, R. Gómez-González, and E. Soto-Regalado, "Studies of adsorption of heavy metals onto spent coffee ground: Equilibrium, regeneration, and dynamic performance in a fixed-bed column," Int. $J$ Chem. Eng., pp. 1-11, 2016.

[17] N. Sebeia, M. Jabli, A. Ghith, Y. El Ghoul, and Alminderej, "Adsorption of anionic-azo dye from aqueous solution by lignocellulose-biomass jute fiber: Equilibrium, kinetics, and thermodynamics study," Int. J. Bio. Macromol, vol. 121, pp. 655-665, 2019.

[18] I. Morosanu, C. Teodosiu, C. Paduraru, D. Ibanescu, and L. Tofan, "Biosorption of lead ions from aqueous effluents by rapeseed biomass," N. Biotechnol, vol. 39, pp. 110-124, 2017.

[19] M. Jafari, M. R. Rahimi, M. Ghaedi, H. Javadian, and A. Asfaram "Fixed-bed column performances of azure-II and auramine-O adsorption by Pinus eldarica stalks activated carbon and its composite with zno nanoparticles: optimization by response surface methodology based on central composite design," J. Colloid Interface Sci., vol. 507, 2017.

Copyright (C) 2019 by the authors. This is an open access article distributed under the Creative Commons Attribution License which permits unrestricted use, distribution, and reproduction in any medium, provided the original work is properly cited (CC BY 4.0).

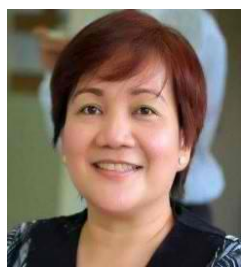

Aileen D. Nieva is the current director of the Mapua University Center for Continuing Education and Special Competencies. She graduated from Mapua University (formerly Mapua Institute of Technology) with a Ph.D. of chemical engineering.

Dr. Nieva has an immense amount of experience and training in technical consultancy and auditing jobs, specializing in waterworks and environmental sector. She is an environmental consultant, registered chemical engineer, certified QMS auditor, and lead auditor for ISO 9001:2008.

She is a professor at Mapua University since 1995 in environmental engineering, chemical engineering, differential equations, air pollution control, and specializing track such as Sustainable Engineering Technology. She received various awards such as Magna Cum Laude (master of science in chemical engineering), Most Outstanding Faculty Member 2002 (School of Chemical Engineering and Chemistry), and more. 